\title{
Mathematical Knowledge of Students who Aspire to Enroll in Engineering Programs
}

\author{
Omar Cuevas ${ }^{1 *}$, Víctor Larios ${ }^{2}$, Julia X. Peralta ${ }^{1}$, Angélica R. Jiménez ${ }^{2}$ \\ ${ }^{1}$ Instituto Tecnológico de Sonora, MÉXICO \\ 2 Universidad Autónoma de Querétaro, MÉXICO \\ *CORRESPONDENCE: $\triangle$ ocuevas@itson.edu.mx
}

\begin{abstract}
Background: The previous knowledge which a student brings with him to university is an important item which eases adaptation and permanence at the university. When a diagnostic exam to evaluate the knowledge students have in Mathematics, their deficiencies from previous studies become clear. At the Instituto Tecnológico de Sonora a diagnostic exam was prepared and given to students who were seeking to enroll in the field of Engineering for the 2016 and 2017 school years.

Material and methods: In the study 1,922 students seeking enrollment in 2016 and 1,184 seeking enrollment in 2017 participated. The exam for the 2016 group was given on computers face-toface in the classroom while the 2017 group was given a distance exam on-line.

Results: The students who took the exam in 2017 received higher percentages of correct answers on the exam than the students from the 2016 group.

Conclusions: However, both groups showed deficiency in mathematical knowledge in various areas such as Arithmetic (problems with applications in context), Geometry, Algebra (factoring, liner equations and $3 \times 3$ lineal equation systems), Analytical Geometry (the four cone figures) and in Calculus (derivative of transcendental functions, limits of a function and maximums and minimums).
\end{abstract}

Keywords: mathematics, university, engineering, previous knowledge

\section{INTRODUCTION}

Educational transition occurs between different levels of schooling-between elementary and middle school, between middle school and high school and between high school and university. In all cases, the educational system must assure that students are ready for the next level, taking into account academic and non-academic factors. During this transition students may meet with failure due to poor achievement, this being due mainly to poor achievement in mathematics and science courses (Culpepper, Basile, Ferguson, Lanning, \& Perkins, 2010). Over the past decades the problems with the transition from high school to university have been studied and in Mexico, as well as in the rest of Latin America, a great deal of research has been carried out during the last 30 years (see, for example Centro Interuniversitario de Desarrollo [Cinda], 2011; Figuera \& Torrado, 2012; Flores, 2016; Larrazolo, Backhoff, \& Tirado, 2013).

Corominas (2001) mentions that the transition from high school to college should be considered within a broad temporal space covering the year previous to and the year following the moment of transition-a moment which may prove easy or difficult, with many obstacles which may lead to dropping out or changing

\footnotetext{
Article History: Received 28 February $2018 \bullet$ Revised 19 June $2018 \bullet$ Accepted 8 July 2018

(C) 2018 The Author(s). Open Access terms of the Creative Commons Attribution 4.0 International License (http://creativecommons.org/licenses/by/4.0/) apply. The license permits unrestricted use, distribution, and reproduction in any medium, on the condition that users give exact credit to the original author(s) and the source, provide a link to the Creative Commons license, and indicate if they made any changes.
} 
schools or areas of study. He also states that the end of the first year of college is when low levels of achievement arise, prolonging a student's stay at the university and this being the period in which the dropout rate among students is the highest.

The many possible situations which may arise during the process of a student's transition to university present challenges for universities (Aguilar, 2011). According to Gómez-Chacón (2009), there is ever-growing consensus that in order to carry out a study of learning difficulties faced by students in transition from high school to college, a multi-perspective approach is necessary: the perception of the student and professor, cognitive indicators on the quality and excellence in the area of knowledge.

Academic preparation proves fundamental to a student's success during the next stage of his education. Determining the previous knowledge of the student who is going to enroll at a university is of upmost importance in order to align this knowledge with the new knowledge he needs to acquire so that he can smoothly adapt to and remain in the university.

Previous knowledge and its impact on learning and academic performance has been the subject of studies over the past years. The interest in the influence of previous knowledge is closely connected to the constructivist focus of learning which has become dominant over the past decades (Haikikari, 2009).

Cadenas (2007) mentions that in order to build new knowledge, it is necessary for students to carry out a re-organization and broadening of their previous knowledge and for teachers to detect shortcomings, difficulties and mistakes which prevent the knowledge which is being acquired from becoming significant.

Moreover, Morales (2009) points out that it is convenient to take into account the student's initial knowledge and to establish a coherent relationship between what the student already knows and the new knowledge he is to acquire. Otherwise unnecessary problems may arise which make the student feel unsure when faced with new knowledge.

Although science has been accepted by many, including students, as the basis for technological development, they still feel that mathematics is not necessary for achieving good results in science courses. Students think mathematics is a difficult subject which many try to avoid (Ogunleye, Awofala, \& Adekoya, 2014).

There are many factors which may affect students' performance in science and math, including academic preparation, the congruence between various education levels, alignment of standards and expectations from one level to the next, as well as various non-academic factors including preparation before enrollment, social relationships, background and parental support, among others (Culpepper, Basile, Ferguson, Lanning, \& Perkins, 2010).

Previous mathematical knowledge is an important factor in the case of Engineering. In general, high school curriculum is designed to prepare students to successfully complete the first semesters of university, but unfortunately this does not happen. In Mexico, as well as in other countries, it seems that the design for the high school curriculum is not effective enough, forcing many universities to offer preparation courses that bring students' knowledge up to the necessary level for enrollment in the university.

When a diagnostic test to evaluate students' previous knowledge of mathematics is given, students' deficiencies in basic content become evident. That is to say, they are deficient in the 'basic' mathematical knowledge which is assumed they should have since the students have studied the contents throughout high school (Mota \& Valles, 2015).

The diagnostic tests used to evaluate students' knowledge may be prepared using various kinds of items, both open-ended and close-ended. The close-ended questions may be either true and false or multiple-choice.

Multiple-choice questions require greater effort and a higher degree of expertise on the part of the person who is drafting the exam and has the advantage of producing a more reliable evaluation. Therefore, multiplechoice questions are the most appropriate resource for studying a large number of subjects (Moreno, Martínez, \& Muñiz, 2004). Most authors believe that multiple-choice exams, by reducing to a minimum human intervention, eliminate subjectivity in the evaluation and inconsistencies in grading which are common to other kinds of exams (Rodríquez, 2008).

One of the criticisms of multiple-choice questions is that they do not allow students to freely prove their knowledge and reasoning but rather evaluate knowledge irrespective of the way in which it is communicated (Arocena, Gascue, \& Leymonié, 2010). Multiple-choice exams encourage guesswork: the factor of guessing 
cannot be excluded from the process of selection of the correct answer (Lou \& Zhang, 2011). This may skew the results and lead to inappropriate decisions being made.

Many universities give their entrance level students multiple-choice exams. This is the scene in the Mathematics Department of the Instituto Tecnológico de Sonora, a university in southern Sonora state which offers the course, Fundamentos de Matemáticas (Fundamentals of Mathematics) within the Engineering program in order to bring students up to the necessary levels in Algebra, Geometry and Trigonometry. This institution gives a Mathematics exam as a prerequisite for enrolling in the program. In 2016 an exam was designed with items from primary through high school level. This exam was given to the students who were applying for studying Engineering in 2016 and 2017. In 2017 the way in which the exam was given was modified, making an analysis of the results essential for analyzing the results in order to establish the pertinence of the exam with respect to students' knowledge of math and the procedure for implementation of the exam. Therefore, the following objectives were established.

\section{GENERAL OBJ ECTIVE}

The general objective is to evaluate the mathematical knowledge of students who applied for studies in Engineering in 2016 and 2017 at a university in southern Sonora, in order to determine students' areas of weaknesses and to establish actions to be taken to improve the teaching-learning process.

\section{SPECIFIC OBJ ECTIVES}

- Analyze the mathematical knowledge of students applying for Engineering in 2016 and 2017.

- Evaluate the academic performance of students applying for Engineering in 2016 and 2017.

- The way in which the diagnostic exam is given impacts the results of academic achievement for students applying to Engineering in 2016 and 2017.

\section{J USTIFICATION}

A proper analysis of previous knowledge of mathematics of students applying for admission to university will bring benefits for the educational institution such as: identifying the most common mistakes students make and making complementary material as backup for the course, Fundamentals of Mathematics, which students must take during their college years; proposing strategies for improving teaching and learning of mathematical concepts; improving the quality of diagnostic evaluations in order to have a more trustworthy instrument for detecting students' deficiencies; and modifying the implementation of the admission exam to improve the process.

\section{METHODOLOGY}

There were 1,922 students who participated in the study, all applicants for admission to study Engineering in 2016. 35.4\% were women. For the 2017 schoolyear 1,184 aspiring students participated, 32.7\% of them women. The age range for both years oscillated between 17 and 19 years old. All students aspiring for enrollment in the Engineering program take a knowledge-based exam and those who do not pass take a course in the Fundamentals of Mathematics, consisting of 15 weeks of face-to-face classes.

The Mathematics Department at the Instituto Tecnológico de Sonora gave the knowledge-based exam, consisting of 36 items to students applying in 2016 and of 21 items to the students applying in 2017.

Both exams were created based on a bank of 111 items and had questions pertaining to Arithmetic, Algebra, Geometry, Trigonometry, Analytical Geometry and Differential Calculus, and were graded based on the level of education where they were introduced, from 4th grade of primary school through the last semester of high school. The subjects included in the primary level were simple operations, fractions, hierarchy of operations, simple rule of three, probability, unit conversions and geometry; for the middle school level decimals, locating points on a straight line, fractions, probability, geometry, compound rule of three, powers and linear equations with one variable were included; and at the high school level topics such as right angle triangles, circumference, unit conversion, operations with fractions, linear equation with two variables, systems of $2 \times 2$ and $3 \times 3$ linear equations, quadratic equations, number lines, factoring, logarithms, oblique 
Table 1. Number of items included in the diagnostic exam

\begin{tabular}{lcc}
\hline Grade & Number of items in 2016 & Number of items in 2017 \\
\hline 4th grade (CP) & 3 & 1 \\
\hline 5th grade (QP) & 3 & 1 \\
\hline 6th grade (SP) & 3 & 1 \\
\hline First year of Middle School (PS) & 3 & 2 \\
\hline Second year of Middle School (SS) & 3 & 2 \\
\hline Third year of Middle School (TS) & 3 & 2 \\
\hline 1st semester of High School (PB) & 3 & 2 \\
\hline 2nd semester of High School (SB) & 3 & 2 \\
\hline 3rd semester of High School (TB) & 3 & 2 \\
\hline 4th semester of High School (CB) & 3 & 2 \\
\hline 5th semester of High School (QB) & 3 & 2 \\
\hline 6th semester of High School (SB) & 3 & 2 \\
\hline
\end{tabular}

angled triangles, straight lines, parabolas, ellipses, function domain, limits, derivatives and maximums and minimums for a polynomial.

The items were chosen at random for each of the 12 years of schooling. Table 1 shows the distribution of the items for each of the exams given, for the years 2016 and 2017.

The focus used in the present study was quantitative which is the method used for studies which collect and analyze data in order to contrast previously established hypothesis. It is supported with the use of statistics in order to establish behavior patterns for the population studied. The design method is nonexperimental since the independent variable which is the object of the study (mathematical knowledge) was not manipulated. It is considered transactional because it deals with one moment in time.

The procedure used in the study is described.

1. The number of items to be used in each exam of mathematical knowledge was determined for each of the two years, 2016 and 2017.

2. The entrance exam was given to students for the year 2016. This was a computer-based exam, face to face in a classroom and the answers were multiple choice.

3. The entrance exam was given to students for the year 2017. This exam was given using a distance mode using a computer connected to Internet. The student accessed the exam anywhere and at any time and the answers were multiple choices. The time limit for the exam was 75 minutes.

The information was gathered and analyzed using descriptive statistics methods, specifically frequency distribution, histograms and pie charts. Inferential statistics were also used. Excel and Minitab14 software were used for the analysis.

\section{RESULTS}

The results of the exams given in 2016 and 2017 were analyzed. To this end the percentage of correct answers obtained by the aspiring students for each grade and for both 2016 and 2017 were obtained. These results are shown in Figure 1. It may be seen that the students in 2016 only had better percentages of correct answers for the questions at the 4th grade level and 5th semester of high school. However, in the hypothesis tests carried out for the two proportions, the difference was non-significant, with a level of significance of 0.01 . For all the other grades, the difference was significant, with a $p$ value less than 0.01 . The greatest differences between the students from the two groups were in 6th grade and 2nd semester of high school. 


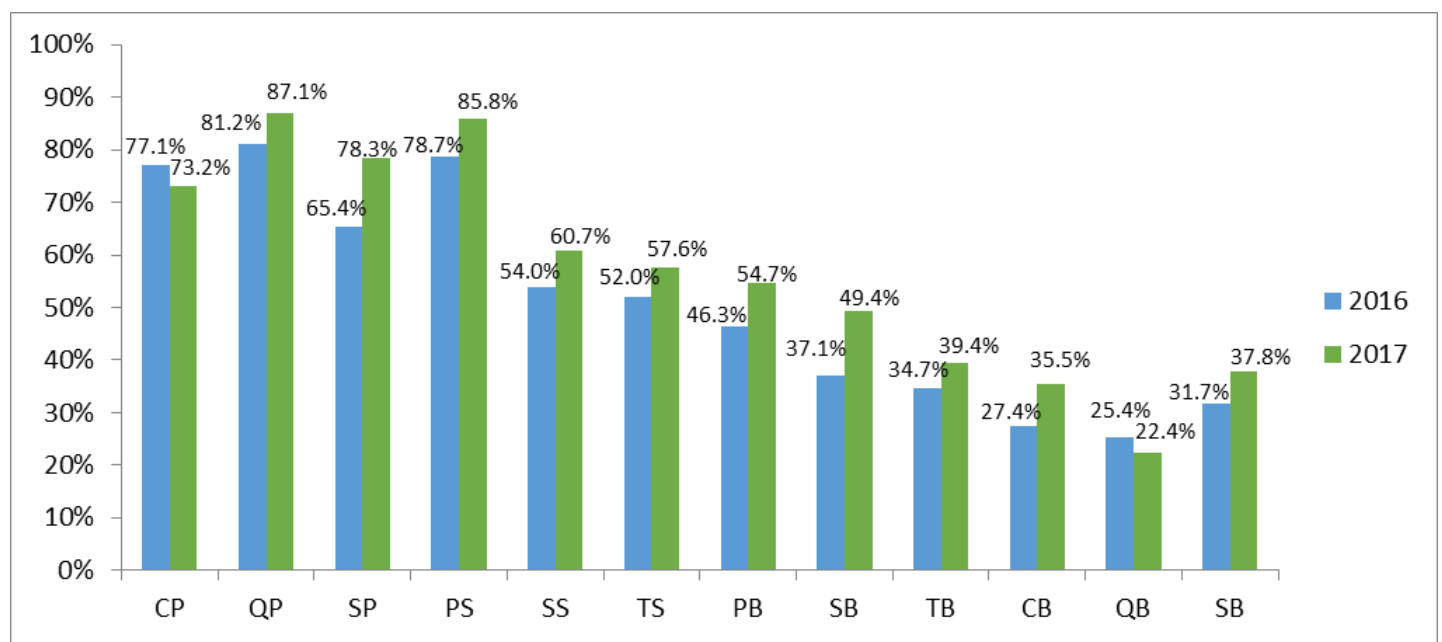

Figure 1. Percentage of correct answers by grade levels for the students tested in 2016 and in 2017

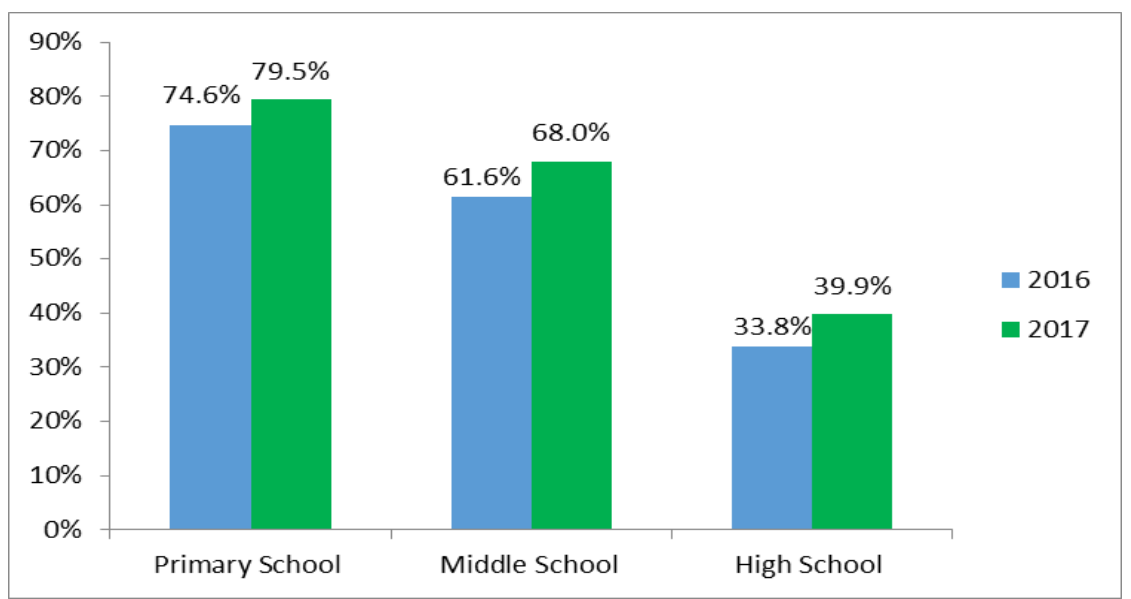

Figure 2. Percentage of correct answers per educational level for students tested in 2016 and 2017

Data for educational level was also analyzed: for Elementary, Middle and High School. Figure 2 shows the percentage of correct answers for aspiring students for both 2016 and 2017 for each of the 3 levels of education. The greatest difference can be seen at the Middle School level, followed by High School and with less difference in Elementary School. However, for both years of aspiring students we can observe major deficiencies. More than $20 \%$ of the students cannot correctly answer questions from the elementary school level; over $30 \%$ cannot correctly answer questions from the middle school level; and over $60 \%$ cannot correctly answer questions from the high school level.

In a study carried out by Backhoff, Ramírez and Dibut (2005) on the implementation of placement exams in mathematics for engineering students at the Universidad de Baja California, many deficiencies in the students' mathematical knowledge were also found. Nearly $50 \%$ of the students' highest level was for Middle School and approximately 38\% had only knowledge at the level of the first year of High School.

Hypothesis testing was carried out for two proportions, the results indicated significant differences at all three levels with a $p$ value of less than 0.001. That is, the students seeking admission in 2017 had a higher percentage of correct answers than the students in 2016, at the elementary, middle and high school levels. It can also be seen that the percentage of correct answers for the high school level does not even reach $30 \%$, for middle school not even $70 \%$ and for elementary school not even $80 \%$.

The percentage of overall correct answers for the students in 2016 was $50.9 \%$ and for 2017 it was $56.8 \%$. The hypothesis test for two proportions proved significant, with a $p$ value less than 0.001 .

The average grade for the 2016 students was 4.43 with a standard deviation of 1.16 . The average for the 2017 students was 5.41 with a standard deviation of 1.55 . The analysis of variance to examine the equality of 
Table 2. Percentage of students seeking admission in 2016 and 2017 who did not correctly answer the indicated problem.

\begin{tabular}{lll}
\hline Item & G-2016 & G-2017 \\
\hline $\begin{array}{l}\text { 1. CP-Problem in a context which involves basic multiplication operations and } \\
\text { converting from kilograms to tons }\end{array}$ & $62 \%$ & $66 \%$ \\
\hline 2. CP-Problems in a context which involves operations with fractions & $48 \%$ & $45 \%$ \\
\hline 3. QP-Identifying a geometric shape (Pyramid) & $60 \%$ & $38 \%$ \\
\hline 4. QP-Calculating the area of a trapeze & $52 \%$ & $33 \%$ \\
\hline 5. SP-Identifying a quadrilateral & $85 \%$ & $44 \%$ \\
\hline 6. SP-Hierarchy of operations & $41 \%$ & $25 \%$ \\
\hline 7. SP-Throwing a dice & $94 \%$ & $94 \%$ \\
\hline 8. PS-Similarity between two figures & $92 \%$ & $52 \%$ \\
\hline 9. SS-Polygons & $49 \%$ & $40 \%$ \\
\hline 10.SS-Finding the value of x so that two fractions are equal & $48 \%$ & $35 \%$ \\
\hline 11.SS-Number sequence & $45 \%$ & $37 \%$ \\
\hline 12.SS-Problem in a mathematical context on the area of a square & $88 \%$ & $88 \%$ \\
\hline 13.SS-Throwing a dice & $65 \%$ & $52 \%$ \\
\hline 14.TS-Problem in a mathematical context on the volume of a cube & $69 \%$ & $66 \%$ \\
\hline 15.TS- Problem in the context in which the rule of three components is used & $66 \%$ & $19 \%$ \\
\hline 16.TS- Problem in a mathematical context which involves finding the perimeter \\
of figures & $86 \%$ & $66 \%$ \\
\hline 17.TS- Problem in a mathematical context of the construction of a triangle & $41 \%$ & $28 \%$ \\
\hline
\end{tabular}

means proved significant with a $p$ value of less than 0.001 , which is the difference in the grades of the 2016 and the 2017 students.

It was contemplated that students with a grade lower than 7 on his diagnostic exam, on a 0 to 10 scale, failed. The percentage of students from 2017 with a failing grade on the exam was $83 \%$ and for the 2016 students was $98.7 \%$, a marked difference between the two groups with low levels of academic performance for both. Miguez, Crisci, Curione, Loureiro and Otegui (2007) found similar results in a study carried out using a diagnostic tool for admission into the Faculty of Engineering at the University of the Republic of Argentina: 85.5\% of the students did not achieve a passing global grade in Mathematics.

Tests were also given in order to compare the average grades for each of the groups by gender. For the 2016 group the difference between men and women was significant, with a $p$ value of 0.005 : men had better averages than women. For the 2017 group there was not a significant difference between men and women.

When comparing the women from both the 2016 and 2017 groups, a significant difference was found with a $p$ value of less than 0.001 . The women in the 2016 group obtained an average grade of 4.33 on the admissions test, while the women in the 2017 group had an average of 5.27.

With respect to the men, there were also significant differences between the two groups, with a $p$ value of less than 0.001 . The men in the 2016 group obtained an average grade of 4.49 on the admission exam, while the men from the 2017 group had an average of 5.48 .

A more detailed analysis of the main difficulties faced by the students of both groups is shown below.

It is important to remember that the database consisted of 111 problems and the exam for the 2016 group consisted of 36 items while the exam for the 2017 group consisted of 21 items, meaning that each item was not solved by the totality of the group. Table 2 shows the percentage of students for each of the groups, 2016 (G2016) and 2017 (G2017), who did not solve the items correctly, taking into account the levels of elementary and middle school only, from 4th grade of elementary school (CP) to the 3rd year of middle school (TS).

As can be observed in Table 2, the students in both groups had deficiencies mainly in Arithmetic problems applied to real contexts and in the area of Geometry. These deficiencies found in Instituto Tecnológico de Sonora students are also found in students from other educational institutions such as the Universidad Politécnica de San Luis Potosí. In a study carried out on incoming students, the results indicated that the students correctly answered more procedural questions (46.7\%) than contextualized questions (37.6\%). This indicated strength in basic concepts but weaknesses in applying knowledge to practical situations (BerlangaRamírez, González-Salas, Zapata-Ramos and Hernández-Sustaita, 2015). Both studies also show deficiencies in problems of hierarchy of operations. 
With respect to the items at the high school level, most of the students (75\%) from both the 2016 and 2017 groups correctly answered the items related to the following subjects: conversion systems (feet to meters), system of $2 \times 2$ equations and those derived from a polynomial. The areas in which both groups had insufficient results were: numerical operations with fractions, factoring, 3x3 equation systems, operations with algebraic fractions, linear equations, circumference, ellipsis, parabolas, hyperbolas, trigonometric derivatives, logarithmic derivatives, exponential derivatives, maximums and minimums of a polynomial and limits of a function.

\section{CONCLUSIONS}

Based on the diagnostic exam given to students seeking enrollment to studies in Engineering in 2016 and 2017, we can draw the following conclusions.

The students seeking admission in 2017 obtained on average significantly higher scores than students from the 2016 group. However, the results for both groups were insufficient: on a scale of 0 to 10 , the average grade was below 5.5. The students from the 2017 group had better results in terms of the percentage of correct answers than the students from the 2016 group, but both were very low, below $50 \%$. $83 \%$ of the students from the 2017 group obtained insufficient results on the exam while for the 2016 group the percentage of students with insufficient results was $98.7 \%$. We can therefore draw the conclusion that both groups' academic performance is very low.

In the 2016 group men received a better average than women while in the 2017 group there was no significant difference between men and women's averages.

The difference between the results of the two groups may be due to the fact that the 2017 has better mathematical knowledge than the 2016 group or to the way in which the exam was given. The 2016 group took a face-to-face in-classroom exam while the 2017 group took a distance exam, solving the problems on line at home or anywhere else.

The students from the 2017 group obtained a higher percentage of correct answers in 10 out the 12 grades which were compared. The students from the 2017 group also obtained better percentages of correct answers for the three comparative education levels. In general, the aspiring students from the 2017 group obtained better percentages of correct answers on the exam than the students from the 2016 group. However, many showed deficient mathematical knowledge in various areas such as Arithmetic (problems with applications in context), Geometry, Algebra (factorizing, linear equations and 3x3 lineal equation systems), Analytical Geometry (four conical figures) and in Calculus (derivatives of transcendental functions, limits of a function and maximum and minimums).

Star and Rittle-Johnson (2009) affirm that success in algebra is widely recognized as critical to students' future success in subsequent math courses and point out the very important role played by the comparison of different methods for improving students' learning algebra, both between and within the various representations such as graphic, symbolic and verbal. Along this same line, as Duval mentions (2009), in mathematics, intellectual activity depends entirely on representations, which are the only means possible for accessing mathematical objects. The use of algebraic strategies for posing and solving mathematical situations (pure and applied) help in understanding the more complex concepts seen in Engineering courses. That is why students should be able to, for example, change from the verbal registry to symbolic registry: to solve problems in context, something which does not occur with the students from both years studied.

Knowledge of the results obtained in this study are pertinent in curricular design and important to be considered as antecedents for the professors of this institution. During their first two years of university studies students will take courses in Calculus and Linear Algebra, thus making knowledge of these areas indispensable for students' understanding mathematical concepts and for their academic success. Harris, Black, Hernandez-Martinez, Pepin and Williams (2014) point out that when mathematics are isolated from their use in Engineering, an opportunity is lost for promoting a perception of the true value of their usefulness in the broadest sense. They mention that students' perceptions would be significantly improved if Engineering programs in Higher Education included suitable examples of applications of the use of mathematics in Engineering.

According to Welder (2006), researchers, professors and experts in curriculum design have found areas of content which they believe contribute to the development of skills which lead to students' success in algebra. They also point out that, before learning Algebra, students should have an understanding of numbers, 
reasoning, percentages, operational hierarchy, equality, algebraic symbolism (including the use of letters), algebraic equations and functions. Students from both years of our study show some deficiencies in such areas as the hierarchy of operations, percentages and algebraic equations. Therefore, giving workshops for students to practice the subjects in which they had the greatest shortcoming and not to contemplate the course of Fundamentals of Mathematics (Geometry and numerical fractions) and to prepare material with technological uses which support the areas of algebra and analytical geometry are recommendable.

It is a good idea to carry out a study using other kinds of exams, such as open answer questions which allow for a more detailed analysis in order to not only detect the areas in which students have shortcomings, but also to determine the errors they make when carrying out various operations and algebraic processes. This would allow for better planning the material and activities needed for the course of Fundamental of Mathematics.

\section{ACKNOWLEDGEMENTS}

Publication funded with the PFCE 2017 resource.

\section{Disclosure statement}

No potential conflict of interest was reported by the authors.

\section{Notes on contributors}

Omar Cuevas - Instituto Tecnológico de Sonora, México.

Víctor Larios - Universidad Autónoma de Querétaro, México.

Julia X. Peralta - Instituto Tecnológico de Sonora, México.

Angélica R. Jiménez - Universidad Autónoma de Querétaro, México.

\section{REFERENCES}

Aguilar, M. C. (2011). La transición a la vida universitaria: Éxito, Fracaso, Cambio y Abandono. Pontificia Universidad Católica Argentina "Santa Maria de los Buenos Aires". Retrieved from http://www.alfaguia.org/alfaguia/files/1319733023_12.pdf

Arocena, R., Gascue, C., \& Leymonié, J. (2010). Evaluación y validación de pruebas parciales de opción múltiple de un curso universitario de primer año. Revista Electrónica de Enseñanza de las Ciencias, 9(3), 737-756. Retrieved from http://ue.fcien.edu.uy/archivos/ART13_Vol9_N3\%202010.PDF

Backhoff, E., Ramírez, J., \& Dibut. (2005). Desarrollo e implementación del examen de ubicación de matemáticas (EXUMAT). Revista de la Educación Superior, 34(136), 19-32. Retrieved from http://publicaciones.anuies.mx/pdfs/revista/Revista136_S1A2ES.pdf

Berlanga-Ramírez, E., González-Salas, J., Zapata-Ramos, C., \& Hernández-Sustaita, M. (2015). Estudio exploratorio de habilidades y conocimientos en álgebra y aritmética en estudiantes de nuevo ingreso de la UPSLP. Revista de Sistemas y Gestión Educativa, 2(3), 547-560. Retrieved from http://www.ecorfan.org/bolivia/researchjournals/Sistemas_y_Gestion_Educativa/vol2num3/17.pdf

Cadenas, R. (2007). Carencias, dificultades y errores en los conocimientos matemáticos en alumnos del primer semestre de la Escuela de Educación de la Universidad de los Andes. Revista ORBIS/Ciencias Humanas, 2(6), 68 -84. Retrieved from http://www.revistaorbis.org.ve/pdf/6/6Art4.pdf

Centro Interuniversitario de Desarrollo [Cinda]. (2011). El proceso de transición entre educación media y superior. Experiencias universitarias. Santiago, Chile: Alfabeta Artes Gráficas. Retrieved from https://www.cinda.cl/download/libros/41-El\%20Proceso\%20de\%20transici\%C3\%B3n\%20entre\%20 educaci\%C3\%B3n\%20media\%20y\%20superior.pdf

Corominas, E. (2001). La transición a los estudios universitarios. Abandono o cambio en el primer año de universidad. Revista de Investigación Educativa, 19(1), 127-151. Retrieved from http://revistas.um.es/rie/article/view/96361/ 
Culpepper, S. A., Basile, C., Ferguson, C. A., Lanning, J. A., \& Perkins, M. A. (2010). Understanding, the transition, between High School and College Mathematics and Science. The Journal of Mathematics and Science: Collaborative Explorations, 12, 157-167. Retrieved from http:/www.vamsc.org/wpcontent/uploads/2016/Journal\%2012/UnderstandingtheTransition.pdf

Duval, R. (2009). Sémiosis, pensée humaine et activité mathématique. Amazônia. Revista de Educação em Ciências e Matemáticas, 6(11), 126-143. Retrieved from http://www.periodicos.ufpa.br/index.php /revistaamazonia/article/view/1708/2113

Figuera, P., \& Torrado, M. (2012). La adaptación y la persistencia académica en la transición en el primer año de universidad: el caso de la Universidad de Barcelona. Presented at I Congreso Internacional e Interuniversitario de Orientación Educativa y Profesional: Rol y retos de la orientación en la Universidad y en la sociedad del siglo XXI, Málaga. Barcelona: Universidad de Barcelona. Retrieved from https://core.ac.uk/download/pdf/16207627.pdf

Flores, Á. H. (2016). Pedagogía matemática: Vinculación entre los niveles medio y superior. Presented at IX Congreso Venezolano de Educación Matemática, 57-69, Barquisimeto, Venezuela: Universidad Pedagógica Experimental Libertador y Asovemat.

Gómez-Chacón, I. M. (2009). Actitudes matemáticas: propuestas para la transición del bachillerato a la universidad. Educación Matemática, 21(3), 5-32. Retrieved from http://www.redalyc.org /articulo.oa?id=40516671002

Hailikari, T. (2009). Assessing University Students' Prior Knowledge, Implications for Theory and Practice. University of Helsinki, Department of Education. Helsinki University Print, Finland. Retrieved from http://citeseerx.ist.psu.edu/viewdoc/download?doi=10.1.1.873.3838\&rep=rep 1\&type=pdf

Harris, D., Black, L., Hernandez-Martinez, P., Pepin, B., \& Williams, J. (2014). Mathematics and its value for engineer-ing students: what are the implications for teaching? International Journal of Mathematical Education in Science and Technology, 46(3), pp. 321-336. https://doi.org/10.1080/0020739X .2014 .979893

Larrazolo, N., Backhoff, E., \& Tirado, F. (2013). Habilidades de razonamiento matemático de estudiantes de educación media superior en México. Revista Mexicana de Investigación Educativa, 18 (59), 1137-1163. Retrieved from http://www.scielo.org.mx/scielo.php?script=sci_arttext\&pid=S140566662013000400006

Míguez, M., Crisci, C., Curione, K., Loureiro, S., \& Otegui, X. (2007). Herramienta diagnóstica al ingreso a facultad de ingeniería: motivación, estrategias de aprendizaje y conocimientos disciplinares. Revista Argentina de Enseñanza de la Ingeniería, (14), 29-37. Retrieved from http://www.ing.unrc.edu.ar /raei/archivos/img/arc_2011-11-23_20_47_54-143.pdf

Morales, E. M, (2009). Los conocimientos previos y su importancia para la comprensión del lenguaje matemático en la educación superior. Revista Universidad, Ciencia y Tecnología, 13(52), 211-222. Retrieved from http://www.uct.unexpo.edu.ve/index.php/uct/article/view/236/0

Moreno, R., Martínez, R. J., \& Muñiz, J. (2004). Directrices para la construcción de ítems de elección múltiple. Psicothema, 16(3), 490-497. Retrieved from http://www.psicothema.com/psicothema.asp?id=3023

Mota, D. J., \& Valles, R. E. (2015). Papel de los conocimientos previos en el aprendizaje de la matemática universitaria. Acta Scientiarum. Education, 37(1), 85-90. Retrieved from http://periodicos.uem.br/ojs /index.php/ActaSciEduc/article/view/21040

Ogunleye, A., Awofala, A. O. A., \& Adekoya, E. (2014). Effect of students' background knowledge of mathematics on senior secondary school students' achievement in physics. Chemistry. Bulgarian Journal of Science Education, 23(6), 863-880. Retrieved from https://www.researchgate.net/publication /287354936_Effect_of_students'_background_knowledge_of_mathematics_on_senior_secondary_school _students'_achievement_in_physics

Rodríguez, R. (2008). La evaluación del conocimiento en medicina. Revista de la Educación Superior, 37(147), 31-42. Retrieved from http://www.redalyc.org/articulo.oa?id=60418920003

Star, J. R., \& Rittle-Johnson, B. (2009). Making algebra work: Instructional strategies that deepen student understanding, within and between representations. ERS Spectrum, 27(2), 11-18.

Welder, R. (2006). Prerequisite Knowledge for the Learning of Algebra. Presented at Hawaii International Conference on Statistics, Mathematics and Related Fields, Honolulu Hawaii, USA. 